\title{
Production and Quality Control of Clean Steel in Ansteel
}

\author{
Liao Yali ${ }^{1, a}$, Yao Yufeng ${ }^{2, b}$ \\ ${ }^{1}$ Institute of Applied Technology, University of Science and Technology Liaoning, 114000,China \\ ${ }^{2}$ Ansteel Engineering Technology Corporation Limited, Liaoning, Anshan 114021, China \\ ayyflyl@163.com , basyaoyufeng@163.com
}

\begin{abstract}
Key words: clean steel, tundish metallurgy, secondary refining, quality control
Abstract: The paper focuses on the production process of clean steel combining with the production practice of Ansteel, and analyses the measures to improve the quality control of clean steel from two aspects: the selection of refractory materials and the tundish metallurgy. Practice has proved that the appropriate choice of refractory materials of refining equipment and reasonable use of tundish metallurgy, taking in the tundish dam, argon blowing, iron powder injection, adding the double slag and other measures which can reduce the metal inclusions below $1 \mu \mathrm{m}$ steel and will effectively control impurity elements in steel $\Sigma(\mathrm{H}, \mathrm{N}, \mathrm{S}, \mathrm{P}, \mathrm{O})<80 \mathrm{ppm}$.
\end{abstract}

\section{Introduction}

With the development of modern industry, the uses of steel plate have been put forward new requirements in all walks of life, such as the structural steel with high welding and high strength performance; sheet steel with high deep drawing; oil well pipe with high strength, high toughness, corrosion resistance to $\mathrm{H}_{2} \mathrm{~S}, \mathrm{CO}_{2}, \mathrm{Cl}^{-}$, and high performance alloy structural steel and so on. These requirements lead to constantly improve the purity of molten steel in steelmaking, which is clean steel production.

The so-called clean steel refers to the steel which has very little non-metallic inclusions and gas containing in it, or the steel with little five harmful elements such as oxygen, sulfur, phosphorus, hydrogen and nitrogen. The pure refers to the impurity content in finished steel is very low; the clean refers to the amount of non metallic inclusions in finished steel is few and small in size. The number of levels of non metallic inclusions or 5 kinds of harmful elements in steel can represent the cleanliness of steel. The size and shape of non-metallic inclusions are a sign of the cleanliness of steel. Generally, the inclusion index $<3 \sim 5 \mathrm{mg} / 10 \mathrm{Kg}$ in steel, the size of inclusions $<10 \sim 30 \mathrm{um}$, $\mathrm{T}[\mathrm{O}]<10 \sim 30 \mathrm{ppm} .[1]$

Clean steel production is a systematic project, so it is necessary to consider the establishment of a clean steel production system from the whole, and should be held in every aspect of steel production, in order to reduce the content of impurities.

This paper focuses on the actual production of Ansteel, expounds the production process of clean steel from tapping to secondary refining, analyses the quality control measures to improve the purity of clean steel from two aspects: the refractory materials selection of refining facilities and tundish metallurgy.

\section{Production process of clean steel}

Today, there are two major processes of iron and steel smelting at home and abroad:

Process I: $\mathrm{BF} \rightarrow$ Pretreatment of hot metal $\rightarrow$ Converter $\rightarrow$ Secondary refining $\rightarrow$ Continuous casting

Process II: Preheating of sponge iron or scrap $\rightarrow$ UHP EAF $\rightarrow$ Secondary refining $\rightarrow$ Continuous casting

Almost 10 million tons molten iron in Ansteel is melted by process I.

The production process of clean steel is mainly concentrated in two aspects:

a: Minimize the content of inclusions in steel as much as possible

The method to reduce the content of inclusion elements is mainly by creating refined thermodynamic and kinetic conditions in the pretreatment and secondary refining equipments. To 
control the inclusions in the steel is mainly to reduce its generation, modify it to promote its floating.

b: Control the inclusions in the steel strictly, including the number, size, distribution, shape and type

Usually the clean steel production process includes the following parts: hot metal pretreatment, converter blowing, slag cut off tapping, slagging off, slag modified, secondary refining (vacuum, blowing, heating, slagging), full protection casting, tundish metallurgy, mold metallurgy and taking various measures such as removing inclusions. [2]

\section{Secondary refining technology}

The secondary refining of the liquid steel is to complete the tasks such as desulfurization, deoxidation, degassing, removal of non-metallic inclusions, adjusting the composition of steel and molten steel temperature in a ladle outside the converter or some special containers.

The secondary refining can be divided into ladle processing and ladle refining.

The characteristics of processing type refining are that the refining time is short (10 30 minutes $)$ and refining task is single, there is no compensation to reduce the temperature of molten steel heating device, simple operation, less equipment investment. Molten steel degassing, desulfurization, composition control and inclusion modification device. Such as vacuum degassing method (RH, DH), vacuum ladle argon blowing method (Gazid), ladle injection (CaSi or other powder processing method (IJ), TN, SL) are such.

The characteristics of ladle furnace refining are the refining time is long (60 180 minutes), with a variety of refining function, a heating device, reduce the compensation temperature of molten steel, suitable for all kinds of high alloy steel and special steel properties (such as ultra pure steel) refining production. Such as vacuum oxygen decarburization method (VOD), vacuum arc heating degassing method (VAD) and ladle furnace method (ASEA-SKF). There is similar argon oxygen decarburization process (AOD). [3]

Many steel companies such as Baosteel, Wuhan steel, Ansteel and TISCO have formed the modern typical process of molten iron pretreatment $\rightarrow$ top-bottom blowing $\rightarrow$ secondary refining $\rightarrow$ continuous casting.

\section{Tundish metallurgy technology}

Tundish is a refractory container between mould and casting ladle. The molten steel after the secondary refining can possibly be polluted when being poured into the tundish. Therefore, the tundish can not be seemed as a simple steel transition container, but a continuous metallurgical reactor. The refining measures in the ladle can be transplanted into tundish to further purify the liquid steel. This is the tundish metallurgy.

The reasons of the inclusions formation and the liquid steel contaminated include: the molten steel reoxidized by the air and oxidizing slag in the ladle; the involvement and oxidation of the ladle slag in the tundish. These inclusions must float and be removed in tundish after going into the mould. Therefore the tundish metallurgy process has the functions of purification, regulation, trimming, refining and heating.[4]

\section{Quality control measures of clean steel production}

\section{Selection of refractory materials in secondary refining furnace}

The measure index of the purity is the inclusion number, type, size, shape and distribution. And a major source of foreign steel impurities is the refractory material eroded and weared from the lining of various smelting equipment. Because the size of the foreign inclusions is large and sporadic distribution, the harm to the performance of steel is greater.[5]Therefore, the selection of refractories used in ladle has great influence to the purity of steel.

The refractory materials used in the ladle in China are aluminum silicate brick, aluminum magnesium (carbon) brick, magnesia brick, magnesia calcium brick and zirconia brick.[6]

\section{Refractory materials in $\mathrm{RH}$ refining furnace}

It is generally used the methods of increasing the circulation and a large number of blowing gas to produce ultra low carbon steel. The increase of circulating flow will increase the wear and tear of 
the refractory lining, also increased the structure spelling and erosion. Therefore, the $\mathrm{MgO}-\mathrm{Cr}_{2} \mathrm{O}_{3}$ lining brick dominates the lining RH - OB.[7]

For the RH furnace refractory bricks with structure peeling and high-temperature spelling, $\mathrm{MgO}$ $\mathrm{C}$ is a suitable refractory material, because in preventing the penetration of slag and thermal shock resistance, $\mathrm{MgO}-\mathrm{C}$ brick is better than $\mathrm{MgO}-\mathrm{Cr}_{2} \mathrm{O}_{3}$ brick. Because the damage form is decarburized layer or slag infiltration layer of a few millimeters thick under the working surface, no cracking exists.

\section{Refractory materials in LF、VAD、ASEA-SKF furnaces}

These three kinds of refining furnaces are all equipped with arc heating device, and the liquid steel is argon stirring (or the use of electromagnetic force stirring), generally refined under the reducing slag, producing low sulfur and low oxygen steel. The refractory materials have to work in the conditions of high temperature (1600 1650 ${ }^{\circ} \mathrm{C}$ ), strong stirring and vacuum in a long time, so the magnesia chrome bricks and dolomite bricks are usually used slag line, while the high purity corundum prefabricated are generally used at electrode circle.[8]

\section{Full use of tundish metallurgical function}

For the production of high purity steel, specific measures of the tundish metallurgy technology are as follows:

(1) Retaining wall with dam [9], argon blowing, ceramic filters and other measures in the tundish, can greatly reduce the non-metallic inclusions in steel, and have achieved remarkable results in production.

(2) Adding the small scraps, blowing iron power and other measures to adjust the temperature of molten steel in the tundish can reduce the molten steel temperature drop during casting in the tundish, close to the liquids temperature of casting, equiaxed crystal zone, and reduce the central segregation.

(3) Feeding aluminum, titanium and boron cored wires to the mold through the center hole of the tundish plug rod, realize adjusting the alloy component slightly, not only increase the yields of easily oxidized elements, but also can avoid the clogging of the nozzle.

(4) Adding double layer slag in the tundish surface of molten steel to absord the floating inclusion[10], or feeding the calcium wire in the tundish to change the shape of $\mathrm{Al}_{2} \mathrm{O}_{3}$ inclusions, to prevent the nozzle clogging.

(5)Using induction heating , plasma heating and other measures in the tundish to control the pouring temperature of molten steel in the $-8{ }^{\circ} \mathrm{C}$ to $+8{ }^{\circ} \mathrm{C}$.

Practice has proved that through the reasonable application of the metallurgical function of tundish, the purity level of clean steel in a steel plant of Ansteel has been significantly improved, and the results are shown in Table 1.

Table 1 Control limit levels of clean steel in a steel plant of Ansteel ( unit : ppm )

\begin{tabular}{|l|c|l|l|l|l|l|}
\hline \multicolumn{1}{|c|}{ steel grade } & $\mathrm{H}$ & $\mathrm{P}$ & $\mathrm{S}$ & $\mathrm{O}$ & $\mathrm{N}$ & $\Sigma$ \\
\hline high - carbon steels & 1.5 & 45 & 11 & 19 & 30.2 & 79.7 \\
\hline low - carbon steels & 0.865 & 25 & 7 & 20.5 & 21 & 74.4 \\
\hline
\end{tabular}

In practice, the reasonable application of metallurgical function and the appropriate selection of refractory material can improve the control ability of the impurity elements and inclusions of typical steel grades in Ansteel.

(1) IF steel: the average content of $\mathrm{T}_{[\mathrm{O}]}$ and[N] in the tundish can be controlled less than 10ppm. The inclusions in the slab are mainly independent distribution of less than $10 \mu \mathrm{m}$ of alumina.

(2) The ultra low carbon steel: the average content of $\mathrm{T}_{[\mathrm{O}]}$ and $[\mathrm{N}]$ in the slab can be controlled under 10ppm. The particle size in silicon steel is almost less than $8 \mu \mathrm{m}$. There is hardly any quality problem due to inclusion.

(3) High grade pipeline steel: the content of [S] in the tundish can be controlled less than 10ppm. The inclusions are mainly small particles of oxysulfide ranged from $2 \mu \mathrm{m}$ to $5 \mu \mathrm{m}$. 
(4) Ball bearing steels: The content of [O] can be realized in less than 8ppm, the category of inclusions in steel is mainly the chain of alumina inclusions, the level of less than $1 \mu \mathrm{m}$.

\section{Conclusions}

In the production of clean steel, the proper refractory materials and metallurgical functions of tundish should be chosen.

1 The magnesia chrome brick and dolomite brick should be used in ladle slag line in ladle refining , electrode circle generally adopts high purity corundum perform can effectively reduce the number and morphology of inclusions in steel;

2 The refining ladle treatment equipment should be used $\mathrm{MgO}-\mathrm{C}$ brick and magnesia chrome brick. 3 The tundish metallurgy functions should be used reasonablely, taking in the tundish dam, argon blowing, blowing powder, double slag and other measures which can greatly reduce the nonmetallic inclusions in the steel, will effectively control impurity elements in steel $\Sigma(H 、 N 、 S$ 、 P、 O ) <80ppm.

4 According to the reasonable application of metallurgical function and the appropriate selection of refractory material, $\mathrm{T}_{[\mathrm{O}]} \leq 8 \mathrm{ppm}$, the inclusions in steel is less than $1 \mu \mathrm{m}$.

\section{References}

[1] Liu Liu, Zeng Jiaqing: Iron \& Steel Vol.35-3 (2000), p.68-72

[2] Liu Zhongzhu, Cai Kaike: Iron \& Steel Vol.35-2 (2000), p.64-69

[3] Liu Liu: Steelmaking Vol.17-4 (2001) , p.1-7

[4] Jing Lin-lin, Yuan Shouqian: Metal Materials and Metallurgy Engineering Vol.39-4 (2011), p.56-59

[5] Lin Yulian: Refractories Vol.44-4 (2010), p.377-382

[6] Jing Bin: Sichuan Metallurgy Vol.29-5 (2007) p.63-64

[7] Hong Xueqin, Li uzhong, Yi Weidong: Refractories Vol.46-2 (2012), p.81-86

[8] Chen Zhaoyou: Refractories Vol.41-1 (2007), p.9-18

[9] Bo Fenghua, Xuli, Li Benhai: Steelmaking Vol.23-4 (2007), p.52-55

[10] Yang Ling-li, BAO Yan-ping: Steelmaking Vol.23-2 (2007), p.34-37 